\title{
Improving the Content of User Requirements
}

\author{
Nigel Bevan \\ Professional Usability Services, 12 King Edwards Gardens, London W3 9RG, UK \\ mail@nigelbevan.com
}

\begin{abstract}
Identifying and defining user requirements is an essential input to good user centred design, but there is little guidance on content. The workshop will share and review examples of user requirements provided by the participants, to generate a contents list that could help practitioners identify and document the relevant requirements.
\end{abstract}

Keywords: Usability, requirements.

\section{Description}

Most existing approaches emphasize the need to understand user requirements in order to provide a basis for good design. They describe the methods that can be used to gather information about users and their tasks (e.g. [1,2]). For example the methods suggested by Courage and Baxter [2] are interviews, surveys, user needs analysis, card sorting, group task analysis, focus groups and field studies. But what are the resulting requirements against which the completed system could be evaluated? The Common Industry Specification for Usability Requirements [3] emphasizes the value of high-level requirements for effectiveness, efficiency and satisfaction. But how should these be complemented by more detailed requirements?

An ISO standards group is attempting to define the contents of a user requirements specification, but this has proved to be unexpectedly difficult to do.

The objective of the workshop is to identify a set of categories of user requirements that cover a range of projects and organizations, which could be used to help practitioners elicit, identify and document the relevant requirements. Participants should have experience of producing user requirements, and provide an (anonymized) example at least one month before the workshop, together with their own suggestions for categorization. Issues to be discussed include:

- Is a common categorization possible or appropriate across different organizations and application domains?

- Is there a difference between user needs and user requirements, and is the same categorization appropriate for both?

- How important is it to include requirements for effectiveness, efficiency and satisfaction?

- Should user requirements always be documented, and is it possible in principle to evaluate whether they have been achieved? 
The most appropriate method for wider dissemination will be discussed at the end of the workshop, with a paper in Interactions or the Journal of Usability Studies being possibilities. The results will also submitted to the ISO standards group for information, and could influence national comments on the draft standards.

\subsection{Organizer}

Nigel Bevan is an independent consultant and researcher with wide industrial experience. He has contributed to many international standards, and is a member of the ISO standards group that is developing a Common Industry Format for User Requirements Specifications. Nigel is co-editor of the Common Industry Format for Context of Use Descriptions and the new version of the ISO standard for usability methods supporting human-centered design. He was a member of the National Academy of Science Committee on Human-System Design Support for Changing Technology.

\section{Schedule}

Overview of the examples and summary of prior discussion and conclusions from review of the examples before the workshop.

Brief presentation of each example with questions for clarification.

Discussion: what are the common principles and situation-specific factors?

Identify topics for detailed discussion, ideally in groups, for example based on application domain, methodology or organization size.

\section{LUNCH}

Discussion of topics.

Report back/suggestions for a contents list that categorizes needs and requirements (guided by the issues identified). The conclusions may be general, or specifically related to particular situations.

Plans for dissemination and any further work.

The timetable provides a framework for discussing these issues, but will be adapted depending on the knowledge and experience of the participants, and the issues that arise from the position papers.

\section{References}

1. Bevan, N., Maguire, M.: User requirements analysis: A review of supporting methods. In: Proceedings of IFIP 17th World Computer Congress (2002)

2. Courage, C., Baxter, K.: Understanding your users. Elsevier, Amsterdam (2005)

3. NIST: Common Industry Specification for Usability—Requirements (2007), http://nist.gov/iusr 